\title{
Harmonization of Political and Administrative Boundaries in Kenya Using GIS: A Case Study of Mavoko Constituency
}

\author{
Kyatu Irene*, Godfrey Makokha, Moses Ngigi \\ Institute of Geomatics, GIS and Remote Sensing (IGGReS), Dedan Kimathi University of Technology, Nyeri, Kenya \\ Email: *geogis.irene24@gmail.com
}

How to cite this paper: Irene, K., Makokha, G. and Ngigi, M. (2017) Harmonization of Political and Administrative Boundaries in Kenya Using GIS: A Case Study of Mavoko Constituency. Journal of Geographic Information System, 9, 141-157.

https://doi.org/10.4236/jgis.2017.92010

Received: February 6, 2017

Accepted: April 27, 2017

Published: April 30, 2017

Copyright $\odot 2017$ by authors and Scientific Research Publishing Inc. This work is licensed under the Creative Commons Attribution International License (CC BY 4.0).

http://creativecommons.org/licenses/by/4.0/

\begin{abstract}
The objective of this research was to harmonize political and administrative boundaries in Mavoko Constituency, Machakos County, Kenya, using geospatial technology and public consultation in order to address the numerous disputes that exist. Specifically, the project focused on analyzing the existing electoral and administrative boundaries in the area of study by identifying all existing gaps and overlaps, rectifying the identified gaps and overlaps and created a web based geo-portal of the harmonized sub location boundaries to enable sharing. This was achieved through first putting the various datasets on the same Spatial Reference System and comparing them in order to identify and rectify them using various geospatial operations, public consultation and field work. The result was a single harmonized layer for the sub location data set for the study area. The project finally developed a customized GIS web based portal for sharing the harmonized Sub location boundary. This was uploaded on an open source platform, which has the capability for offline use in the field. The project worked on a hypothesis that if the sub location boundaries adopted by the various Government and Public organizations and individuals doing any kind of mapping in Kenya was a single harmonized data set, the emerging issues on boundary disputes between Counties, Constituencies and County Assembly Wards (CAW's) would not occur. This is because there would be authentic, consisted and authoritative geo-information which maintains a harmonized, consistent, reusable and readily available data. The development of the geo portal ensured that the results of the research are easily accessible on www.msc2015boundariesmavoko.info.ke/mavoko.
\end{abstract}

\section{Keywords}

Boundaries, Data Sharing, Geo Portal, GIS, Harmonization 


\section{Introduction}

This project reviewed administrative boundaries at the sub location level, electoral boundaries at the three levels of \{County Assembly Ward (CAW), Constituency and County\} and the enumeration area boundaries used by the Kenya National Bureau of Statistics (KNBS) in doing their 2009 population and housing census. The purpose of this review was to determine the specific inconsistencies in the datasets, and find ways of harmonizing them in order to solve the numerous discrepancies that exist. Kenya undertook the last boundaries delimitation in 2012 in a process that involved collection and analysis of the 2009 Kenya National Population and Housing Census, existing administrative boundaries and input from the public through public participation. This was in an effort to achieve population quota as defined in the constitution. The population quota is obtained in accordance with chapter seven article 89 section (12) of the constitution of Kenya, by dividing the national population by the number of constituencies or wards as applicable, into which Kenya is divided [1].

The main objective of the research was to harmonize political and administrative boundaries in Mavoko using geospatial techniques and public consultation in order to address the numerous disputes that exist. In specific the research sought to analyze the existing electoral and administrative boundaries in the area of study by identifying all existing gaps and overlaps then rectify the identified gaps and overlaps between the electoral and administrative boundaries. Finally a web-based geo-portal to enable sharing of the harmonized sub location boundary data was created.

\section{Study Area}

Mavoko Constituency is geographically located in Machakos County, Kenya as shown on Figure 1. It has four CAWs namely Syokimau/Mlolongo, Muthwani, Athi River and Kinanie with a total population of 139,502 persons and an approximate area of $843.20 \mathrm{Km}^{2}$ (National Census, 2009) [2]. Mavoko Constituency borders four counties of Nairobi, Kajiado, Kiambu and Machakos in which it belongs. This makes it a perfect study area because it addresses similar problems that exist in other parts of the country. Due to its proximity to Nairobi, it has both rural and urban areas set up. The land tenure systems in the area are varied with both freehold and leasehold tenure systems which have both general and fixed boundaries.

\section{Methods and Materials}

The project identified both spatial and non-spatial data acquired for use. The spatial data sets included the existing maps and plans, the data picked from the field and the ArcGIS online satellite imagery used as training data. The nonspatial data sets included the various acts of parliament, statistical data from the KNBS 2009 population and housing census survey, GPS data picked from the field and the minutes from stake holder consultative meetings held. Two sub location layers of KNBS and IEBC were overlaid with topographical sheets of the 

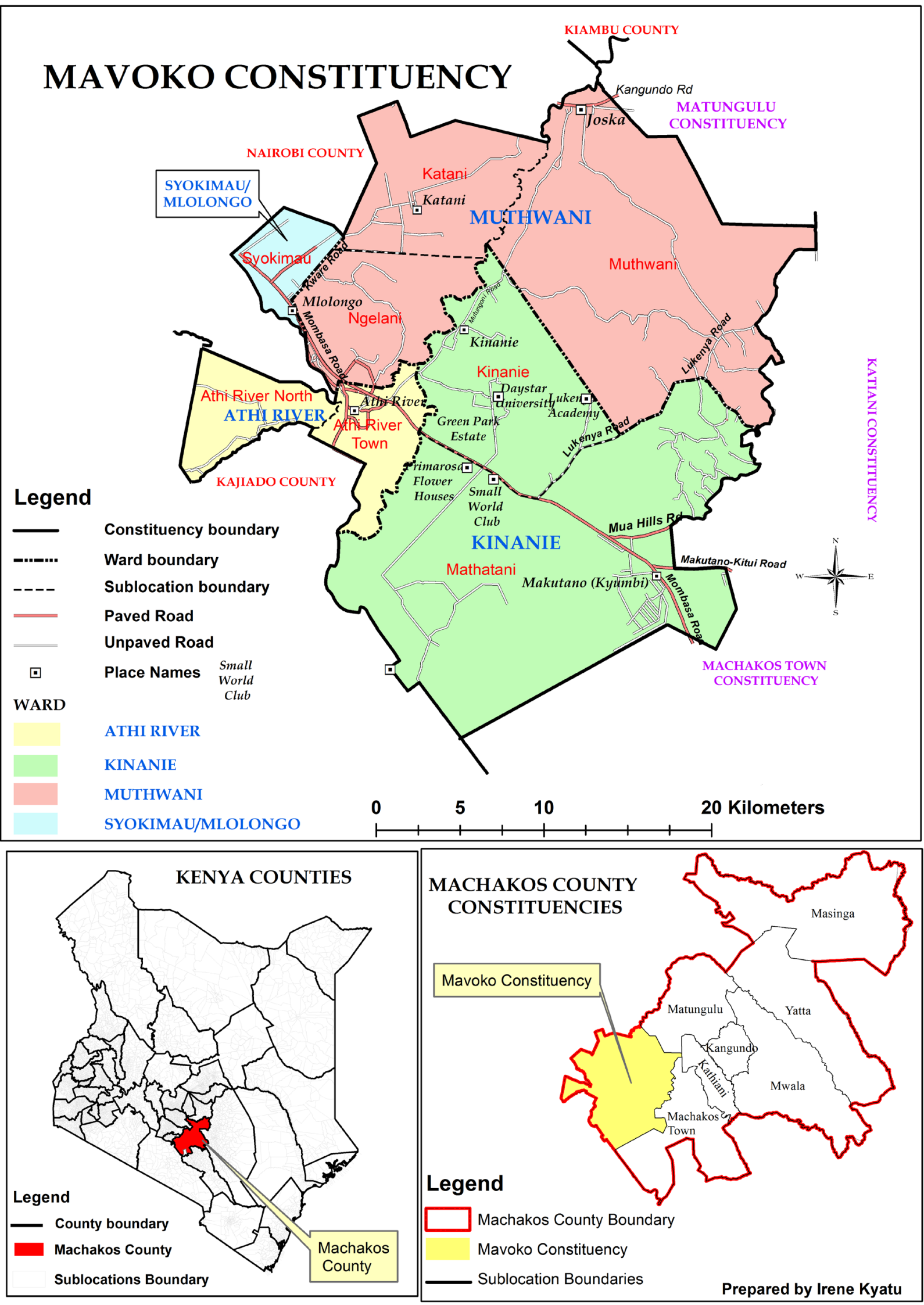

Figure 1. Study area. 
area, put on a common spatial reference system and compared. Errors were checked; minor errors identified whose threshold was above the maximum allowed. Major gaps and overlaps were identified and these required to be aligned. All the errors were solved case by case manually in the appropriate manner. The result of all these was a harmonized Sub-Location boundary for the study area.

\subsection{Datasets and Data Sources}

The research used various data sets including the Constitution of Kenya 2010, the District and Provinces Act, 1992, the National Government Co-ordination Act, 2013, digital Electoral maps from IEBC, digital Administrative and 1: 50,000 Topographic maps from Survey of Kenya (SOK), digital Census maps from Kenya Bureau of Statistics. Table 1 shows the various data sets and their origin metadata.

\subsection{Data Preparation and Analysis}

The first task was to overlay the various spatial datasets involved in the alignment and put them into a common Spatial Reference System. Cleaning and removal of unnecessary geometries and matching the corresponding objects in the datasets was also done [3].

Flowchart on the Alignment Methodology in Figure 2 below shows the first part of the two part methodology undertaken in the research.

\subsection{Spatial Reference System}

The two boundary data sets were in different reference system, thus there was need to harmonize them in to a common one for them to be integrated for

Table 1. Datasets and data sources.

\begin{tabular}{|c|c|c|c|c|c|c|}
\hline Source & Origin & $\begin{array}{c}\text { Date of } \\
\text { Publication }\end{array}$ & Extent & $\begin{array}{c}\text { Scale/ } \\
\text { Resolution/ } \\
\text { Accuracy }\end{array}$ & Projection & Format \\
\hline IEBC & Data set & $1970 \mathrm{~s}$ & Kenya & $1: 3,000,000$ & UTM Arc1960 & shape files \\
\hline KNBS & HRSI & & 2hic009 & Kenya & $1: 3,000,000$ & $\begin{array}{c}\text { UTM } \\
\text { Arc1960 }\end{array}$ \\
\hline $\begin{array}{c}\text { Auxiliary } \\
\text { Data }\end{array}$ & $\mathrm{KRB}$, & & & & & $\begin{array}{c}\text { Auxiliary } \\
\text { Data }\end{array}$ \\
\hline $\begin{array}{c}\text { Topographic } \\
\text { Sheets }\end{array}$ & $\begin{array}{c}\text { Aerial } \\
\text { Photographs }\end{array}$ & $\begin{array}{l}\text { 148/4: } 1975 \\
\text { 149/3: } 1973 \\
\text { 161/2: } 1973 \\
\text { 162/1: } 1973\end{array}$ & $27 \mathrm{KM}$ & $\begin{array}{c}\text { Topographic } \\
\text { Sheets }\end{array}$ & $\begin{array}{c}\text { Aerial } \\
\text { Photographs }\end{array}$ & 148/4: 1975 \\
\hline $\begin{array}{l}\text { Satellite } \\
\text { Images }\end{array}$ & Space & 2016 & World & $<1$ Meters & & $\begin{array}{l}\text { ArcGIS } \\
\text { online }\end{array}$ \\
\hline GPS Data & Field Work & 2016 & Study Area & 3 Meters & UTM WGS84 & shape files \\
\hline $\begin{array}{l}\text { Training } \\
\text { aid }\end{array}$ & $\begin{array}{c}\text { Google Earth, } \\
\text { Google Map } \\
\text { and Open } \\
\text { Street Map }\end{array}$ & Current & $\begin{array}{c}\text { Training } \\
\text { aid }\end{array}$ & $\begin{array}{c}\text { Google Earth, } \\
\text { Google Map } \\
\text { and Open } \\
\text { Street Map }\end{array}$ & Current & Training aid \\
\hline
\end{tabular}




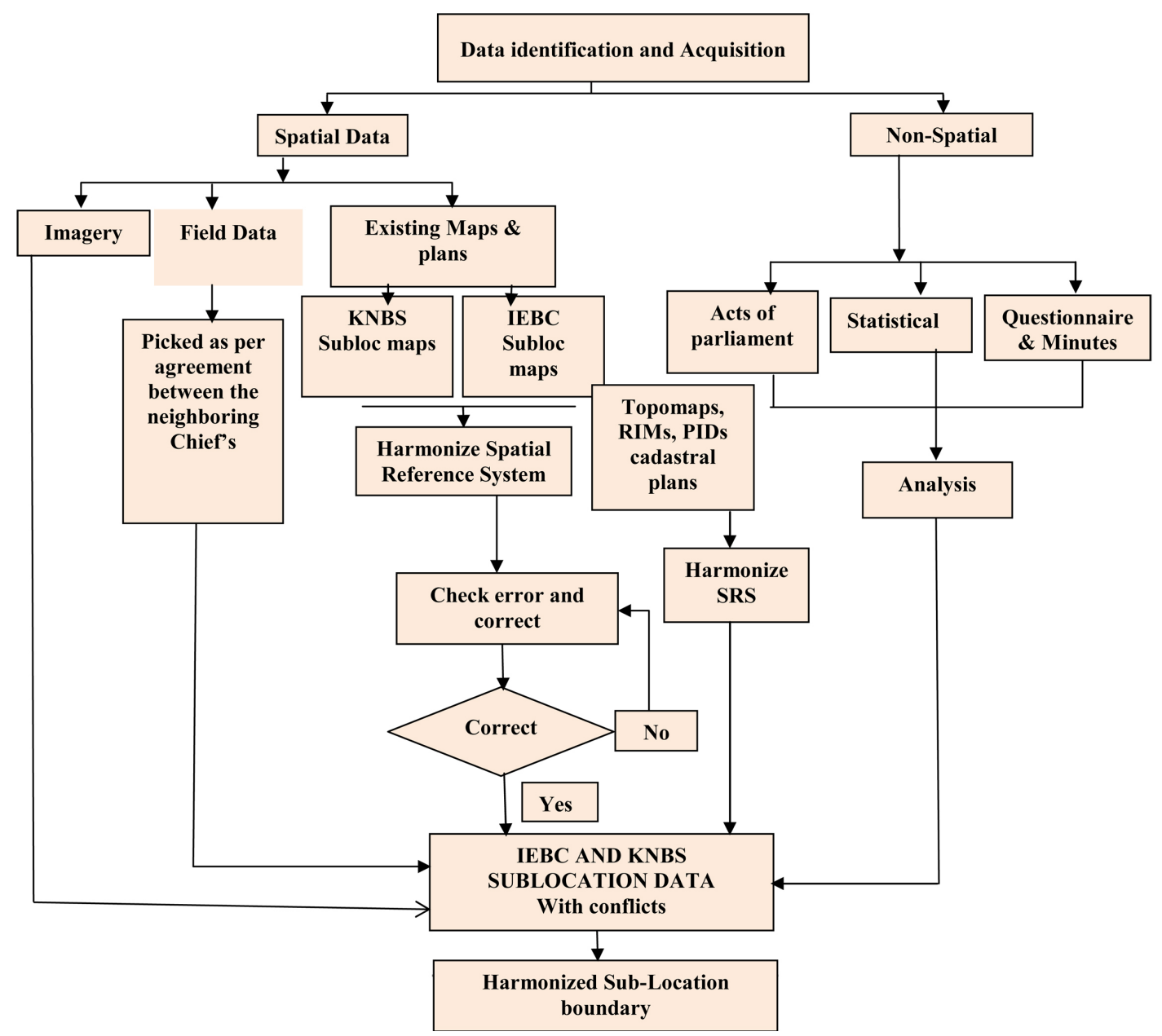

Figure 2. Overview methodology flow chart 1.

accurate viewing and analysis. In Arc Toolbox data management tools, projections and transformations the data were projected to geographic coordinate system WGS84 as shown in Figure 3. This was adopted in order to enable web mapping as most online platforms use this coordinate system. The IEBC data was in Arc 1960, thus it had to be projected to WGS84.

\subsection{Geo Portal Design}

Once the harmonized boundary was achieved, a web-based GIS portal for it was designed and populated in order to demonstrate the system's functionality for sharing with the Geospatial community and any other users. It features a full screen mobile-friendly map template with responsive navbar and modal placeholders, jQuery loading of external GeoJSON files, logical multiple layer marker clustering via the leaflet maker cluster plugin and a client-side multi-layer feature search with auto-complete using typeahead.js. The portal also has a responsive sidebar feature list synced with map bounds, which includes sorting and filtering via list.js. Marker icons included in grouped layer control via the grouped layer control plugin [4].

Softwares used for the study. The Software used for the research were Quantum 


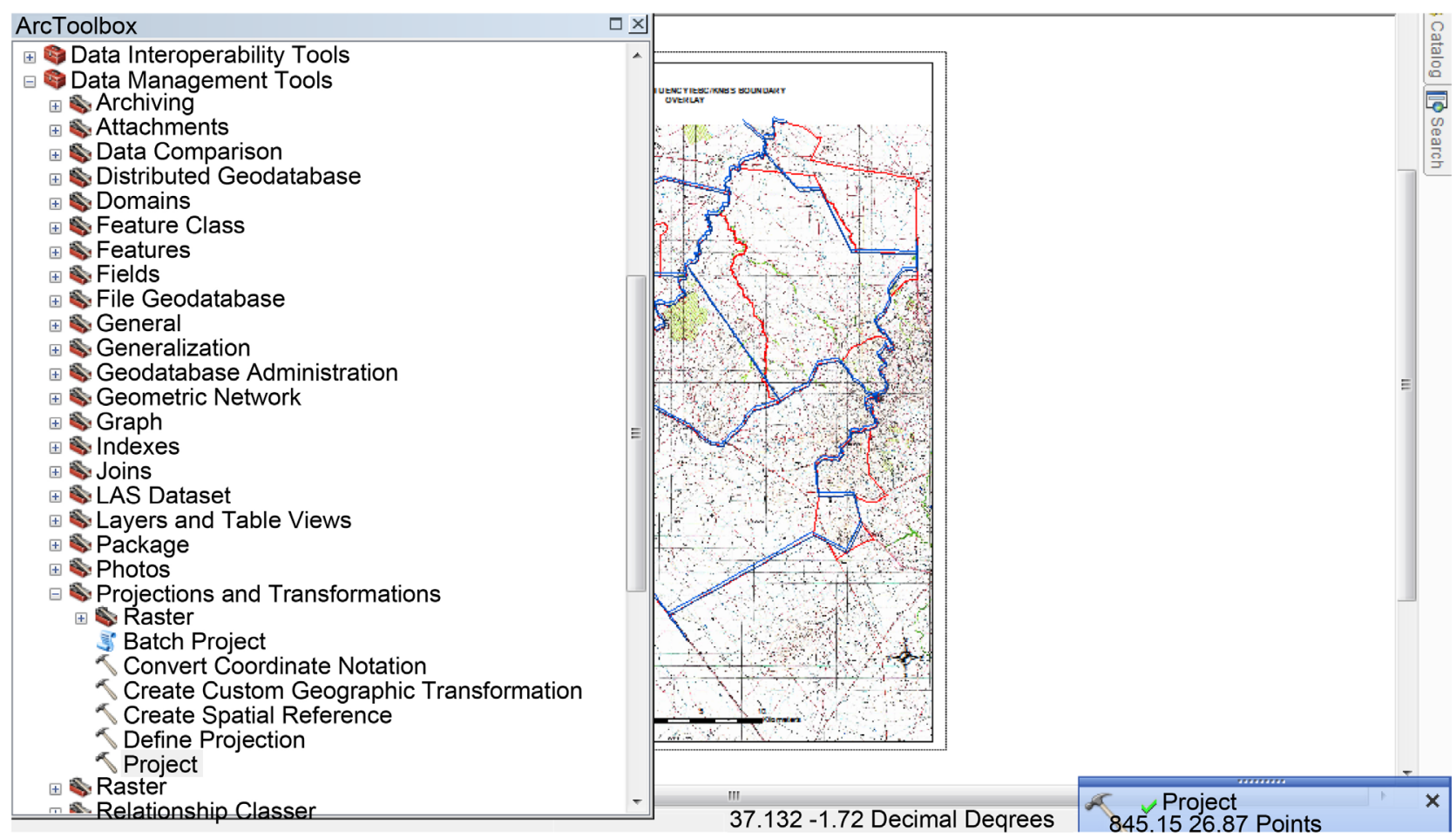

Figure 3. Boundaries after the harmonization of the spatial reference system.

GIS, PostgreSQL with PostGIS, Mapbox, Bootstrap 3, Leaflet, and typeahead.js and Bitnami Wampstack Apache

\subsection{Geo Portal Design Methodology}

Once the harmonized boundary was achieved, a web-based GIS portal for it was designed and the resultant shape-file imported. After the database creation, it was linked to Qgis. This enabled the administrator to add features directly to the database. This was done by using PostGis in Qgis, database, DBmanager, and then connected to a localhost in postgres by creating a new creation in the steps shown in the methodology flow chart 2 in Figure 4.

\subsection{Server Service and Spatial Database Creation}

The research project used a single PostgreSQL server service to store the data. PostgreSQL 9.4 was downloaded and installed from the web site [5], in the default c/program files/postgres and port 5432. PostGIS add-on was added by using the postgreSQL application stack builder. To check whether postGIS was installed clicking the 10th icon on the pdAdmin toolbar. Mavoko database was created on the PostgreSQL server by converting the shape files to their corresponding tables in a PostgreSQL database using the import shape file plugin in PostGIS extension. This was done by right clicking databases, new database in the PgAdmin III. extension.

\subsection{Create Extensions}

To load a new extension into on the Mavoko database SQL plane, the following 


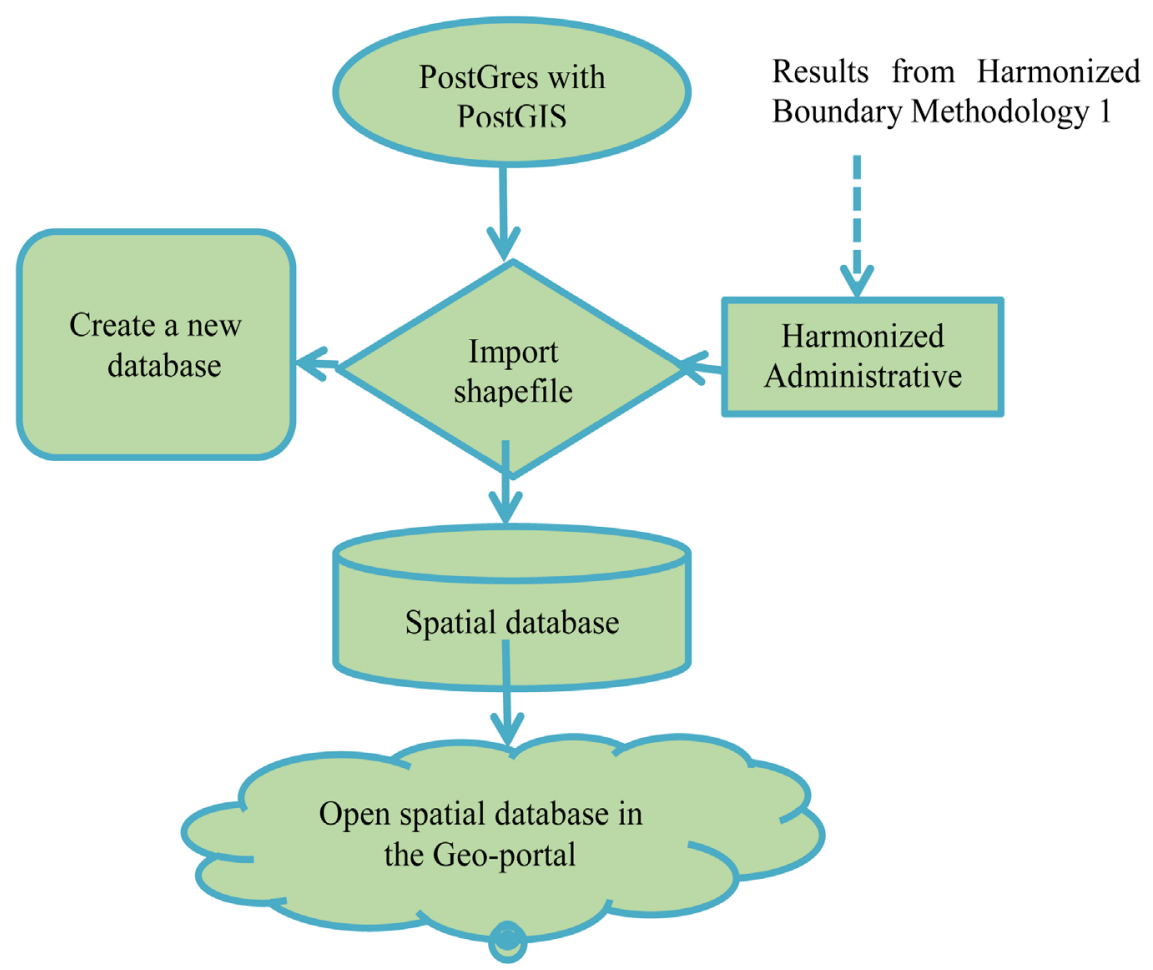

Figure 4. Overview of the methodology flow chart 2.

code was typed and executed as shown on Figure 5. This was typically to create new SQL objects such as functions, data types, operators and index support methods. CREATE EXTENSION additionally records the identities of all the created objects, so that they can be dropped again if DROP EXTENSION is issued [6].

CREATE EXTENSION IF NOT EXISTS postgis;

CREATE EXTENSION IF NOT EXISTS postgis_topology;

CREATE EXTENSION IF NOT EXISTS adminpack;

\subsection{PostGIS Connection}

On the PostGIS shape-file and Dbf loader, a connection was done to the database then the shape files were added by importing them to PostgreSQL database tables using the shape file import manager plugin in PostGIS.

\subsection{Tables}

Tables which are the workhorses for the database for spatial functions meta-data were automatically created in the database's public schema. The SPATIAL_REF_ SYS table and the GEOMETRY_COLUMNS table. The SPATIAL_REF_SYS table holds EPSG IDs and descriptions of the coordinate systems used in the spatial database [7]. By right clicking on the table, it was confirmed that the geometry column was present as shown below in Figure 6, thus a successful upload. These tables contain all the attributes of the imported shape files including the coordinates and geometry that define each feature. 


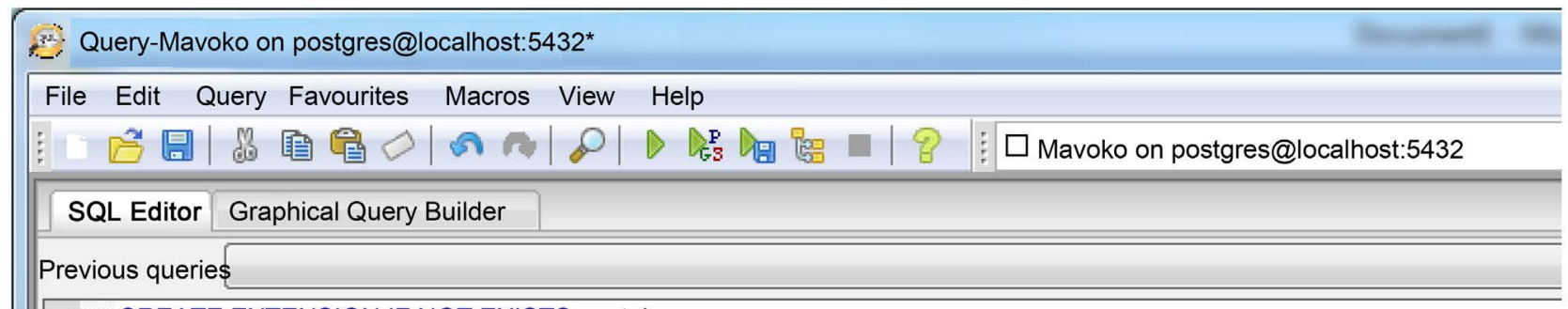

CREATE EXTENSION IF NOT EXISTS postgis;

CREATE EXTENSION IF NOT EXISTS postgis_topology;

CREATE EXTENSION IF NOT EXISTS adminpack;

Figure 5. SQQuery on Mavoko database.

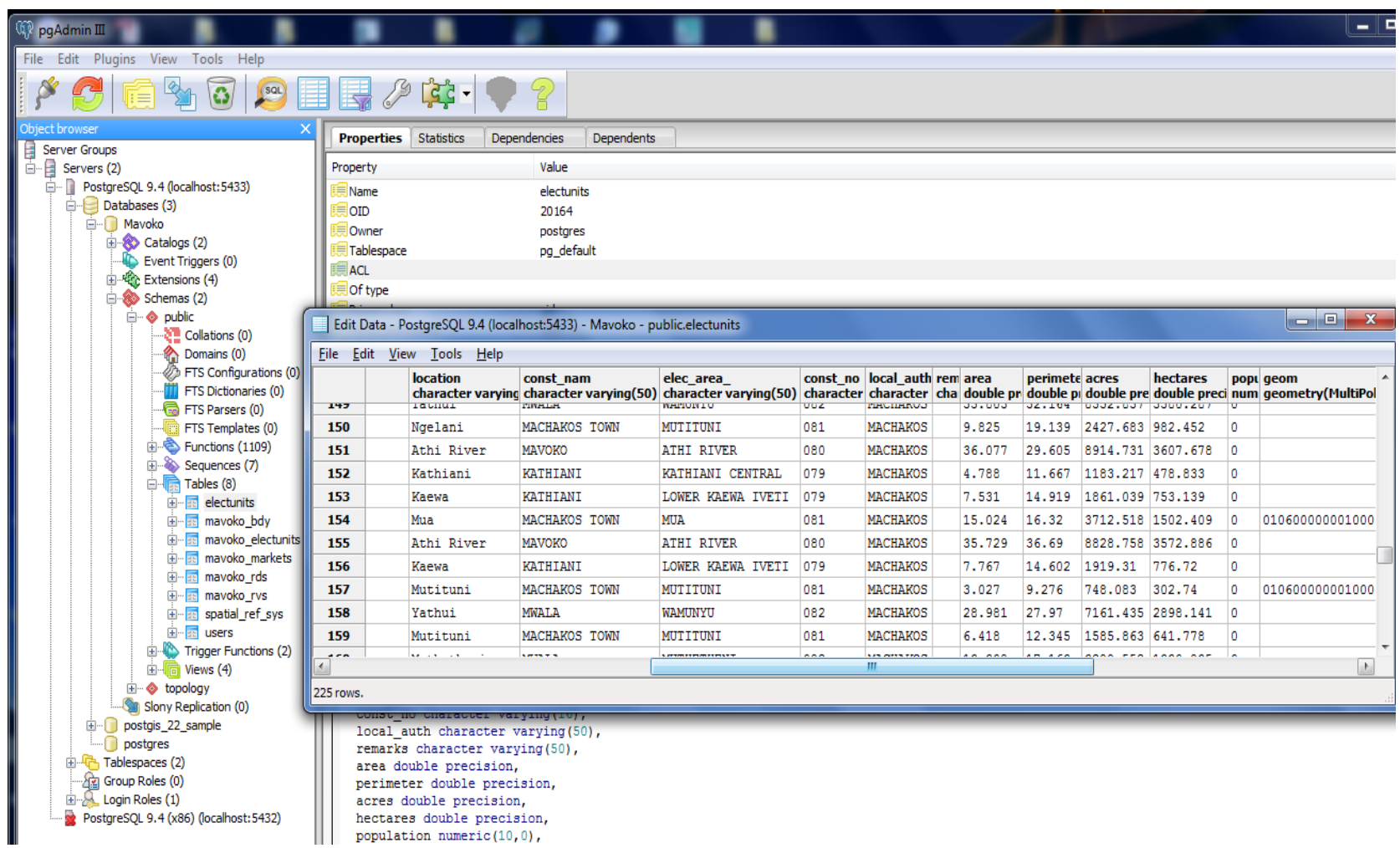

Figure 6. Displaying the spatial database attributes of the shape files imported.

\section{Results and Discussion}

\subsection{Boundary Harmonization}

Once the datasets were acquired they were put under a common special reference system as shown in Figure 7. The research identified several minor errors as shown in Figure 8 and corrected one by one. The PDA 2012 was used to harmonize the county boundaries. The existing Harmonized Boundary Maps Figure 9 were used to ascertain the correct boundaries between constituencies. This is because most constituency boundaries follow the already defined $\mathrm{Mu}$ nicipal and County Boundaries. 


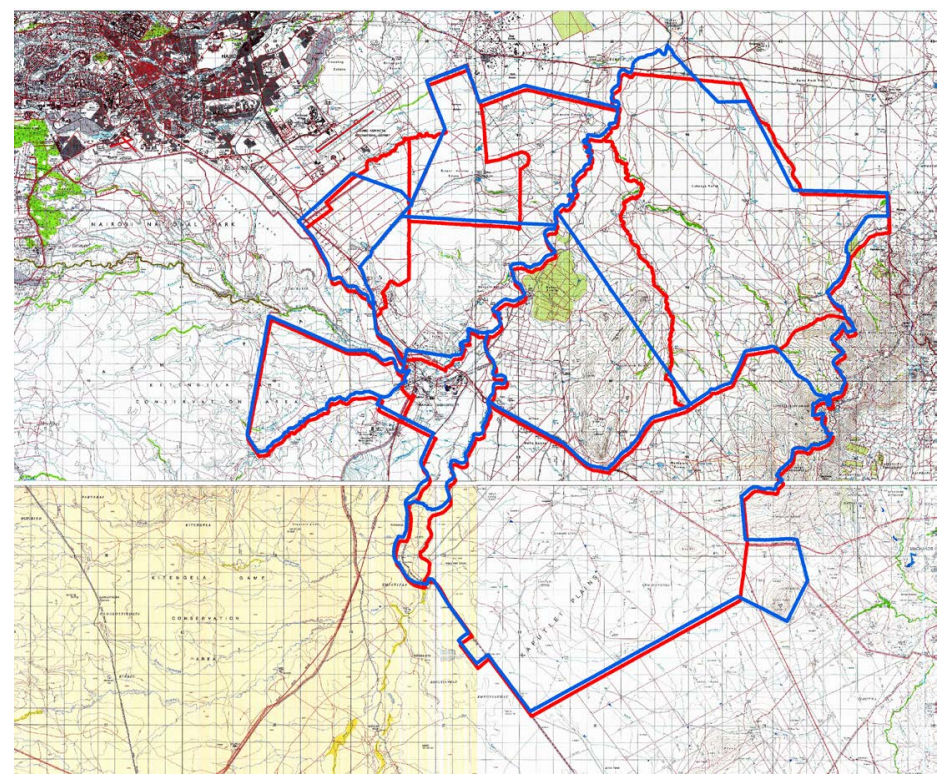

Figure 7. Boundaries after the harmonization of the spatial reference system.

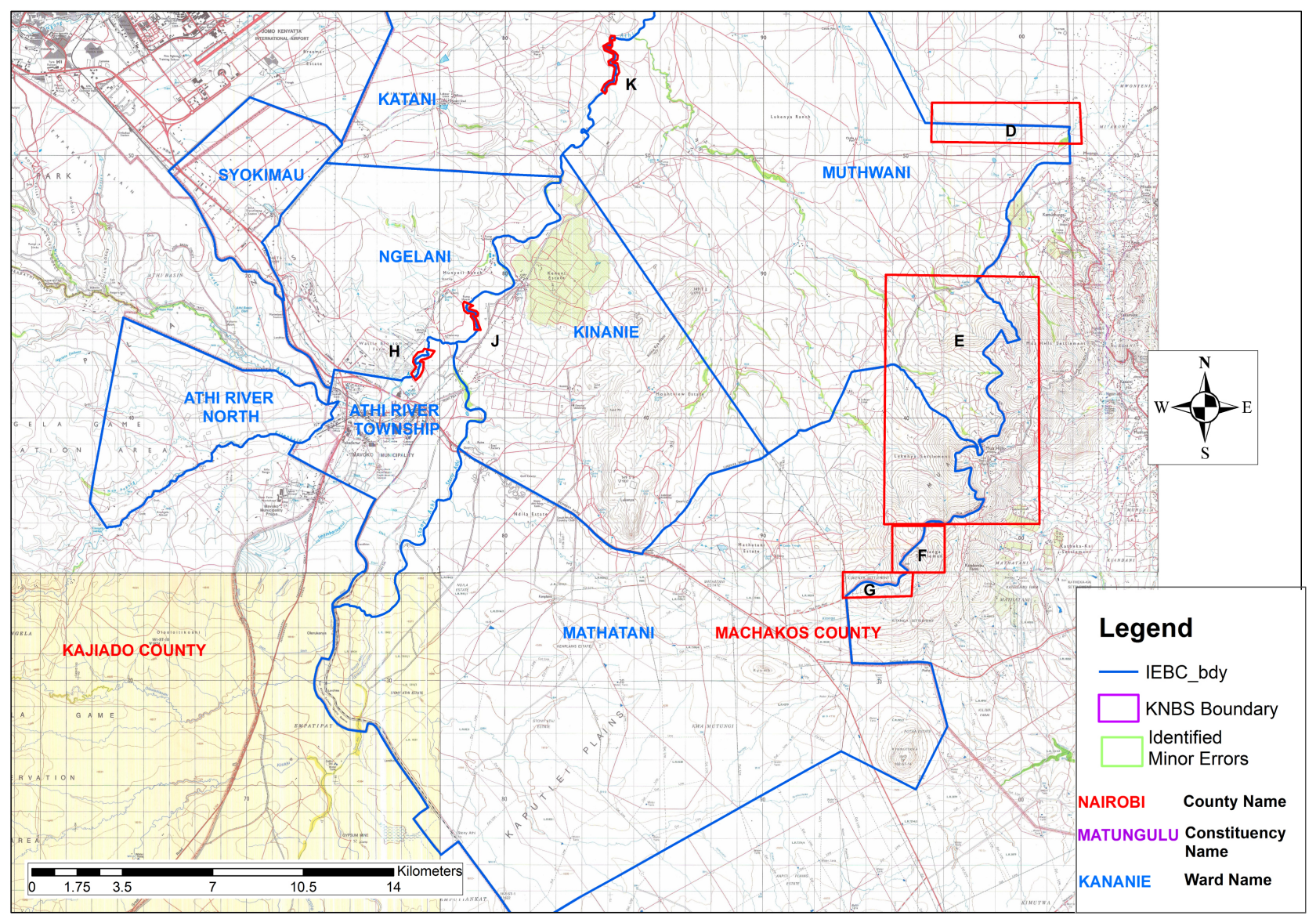

Figure 8. Minor errors identified.

\subsection{County Boundaries Harmonization.}

Kenya Counties were established under the PDA 2012, this act was used to replot 


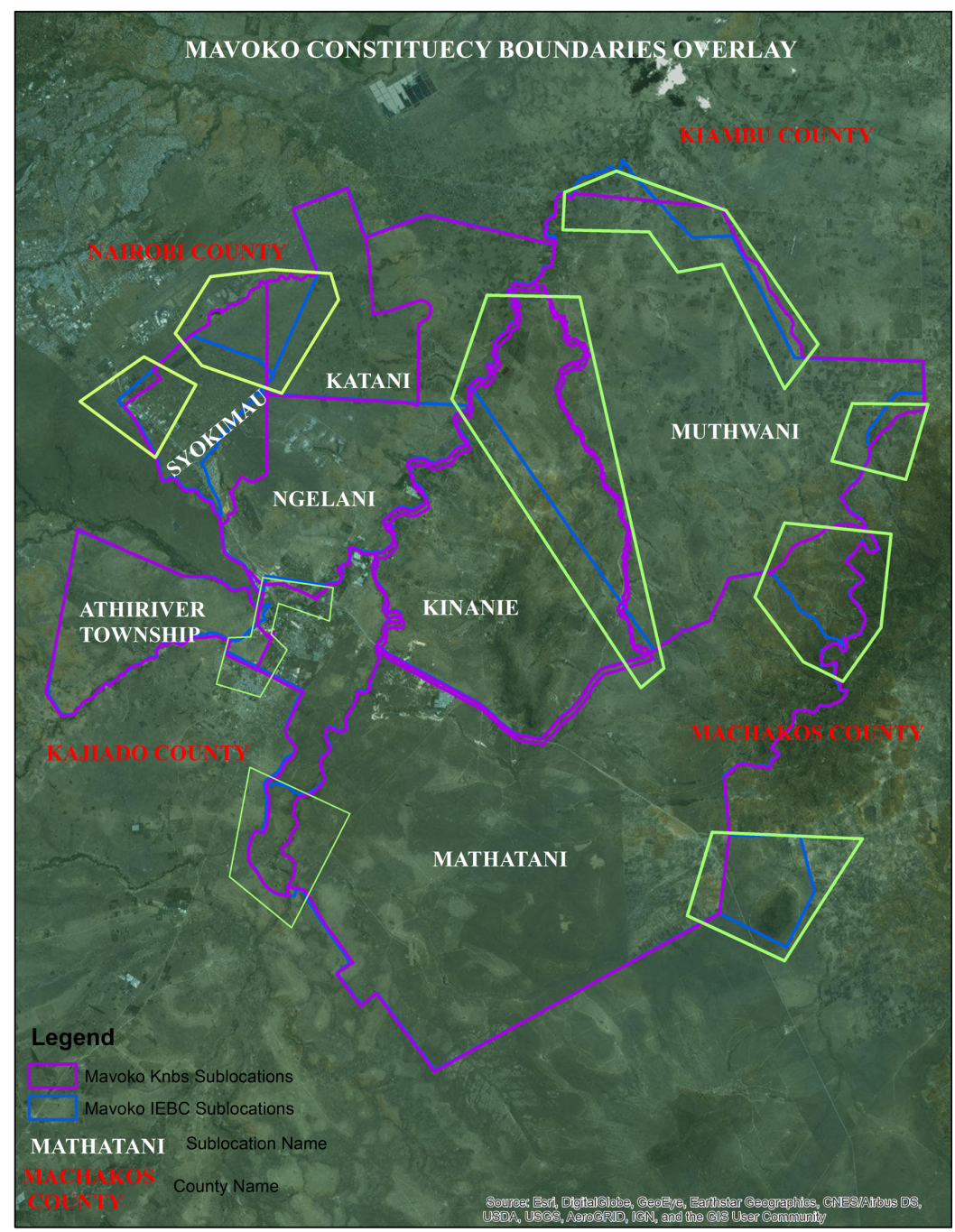

Figure 9. Major gaps and overlaps identified.

the county boundary between the Nairobi and Machakos Counties in order to ascertain the correct boundary line [8]. Figure 10 shows the newly plotted boundary overlaid on 1:50,000 Topographical Maps and on Figure 11 overlaid on ArcGIS Online Satellite imagery.

\subsection{Harmonization of Constituency Boundaries Using Existing Municipal Council Boundary}

The research realized that the two departments have different opinion on the boundary between adjacent administrative regions which make up the Muthwani and Mathatani CAW's, Kinanie and Muthwani CAW's, Syokimau and Ngelani CAW's and Athi River Township and Athi River North CAW's. To harmonize these boundaries, the research adopted the Harmonized Boundary (HB) Plan No. 22 that covers Machakos Municipality, HB 24(C) covering Mavoko Municipality and HB 24(D) covering Kangundo Town Council. These maps clearely showed the extent of each town, thus aking it possible to harmonize the boundaries. Figure 12 shows the Boundary overlaid on the HB Plans and Figure 13 


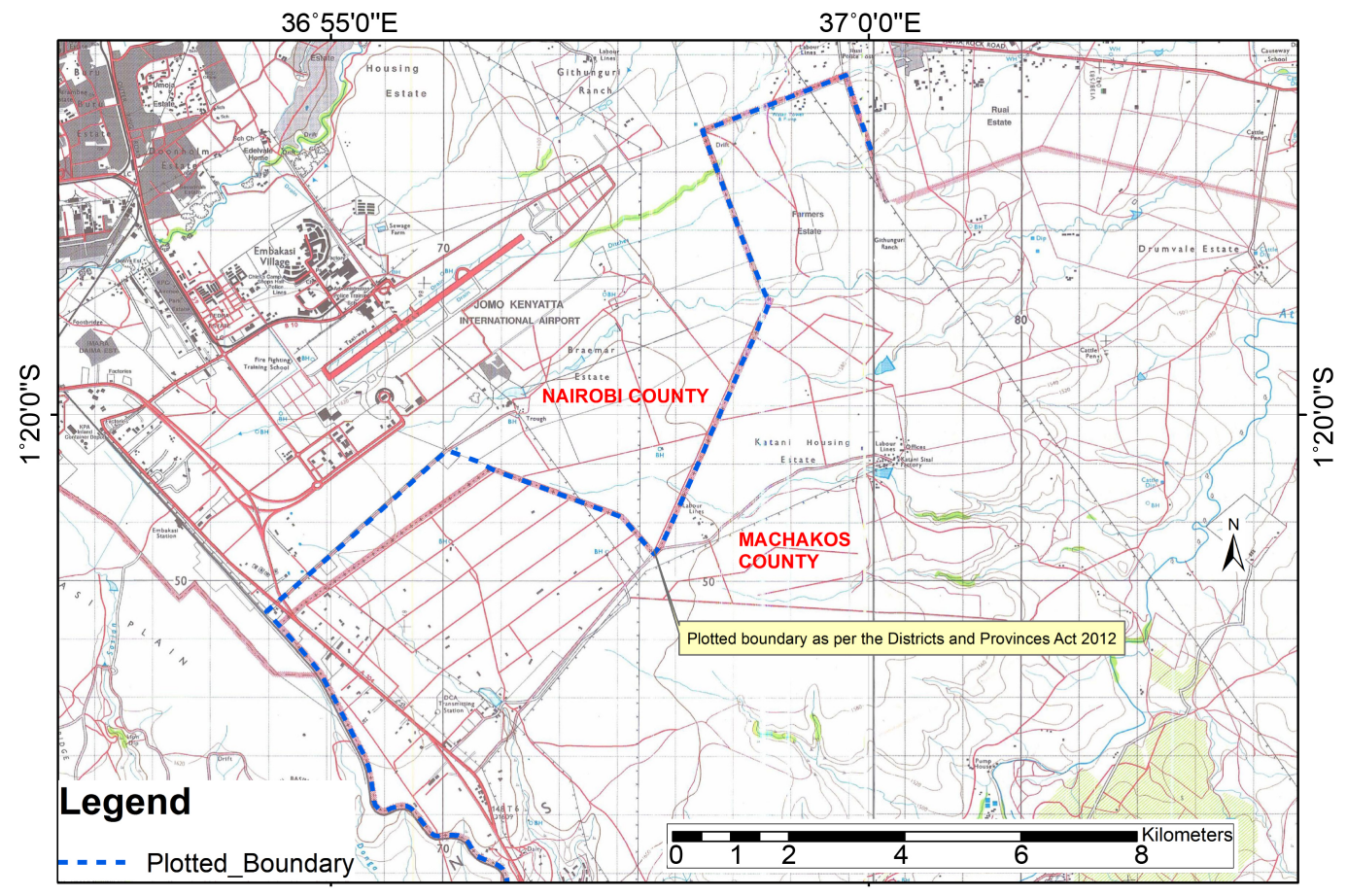

Figure 10. Harmonized boundary plotted using PDA Act 2012 on topographical maps.

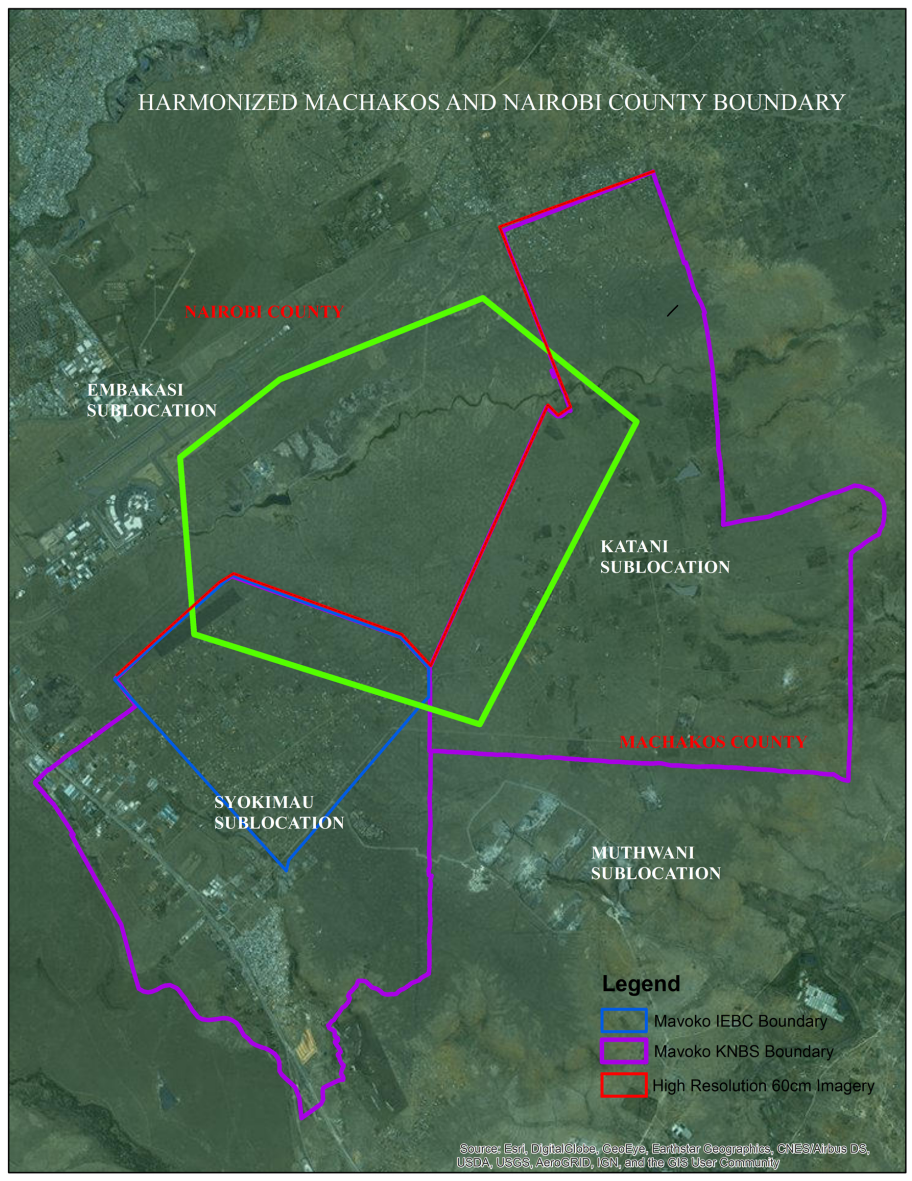

Figure 11. Harmonized boundary plotted using PDA Act 2012 on ArcGIS online satellite image. 


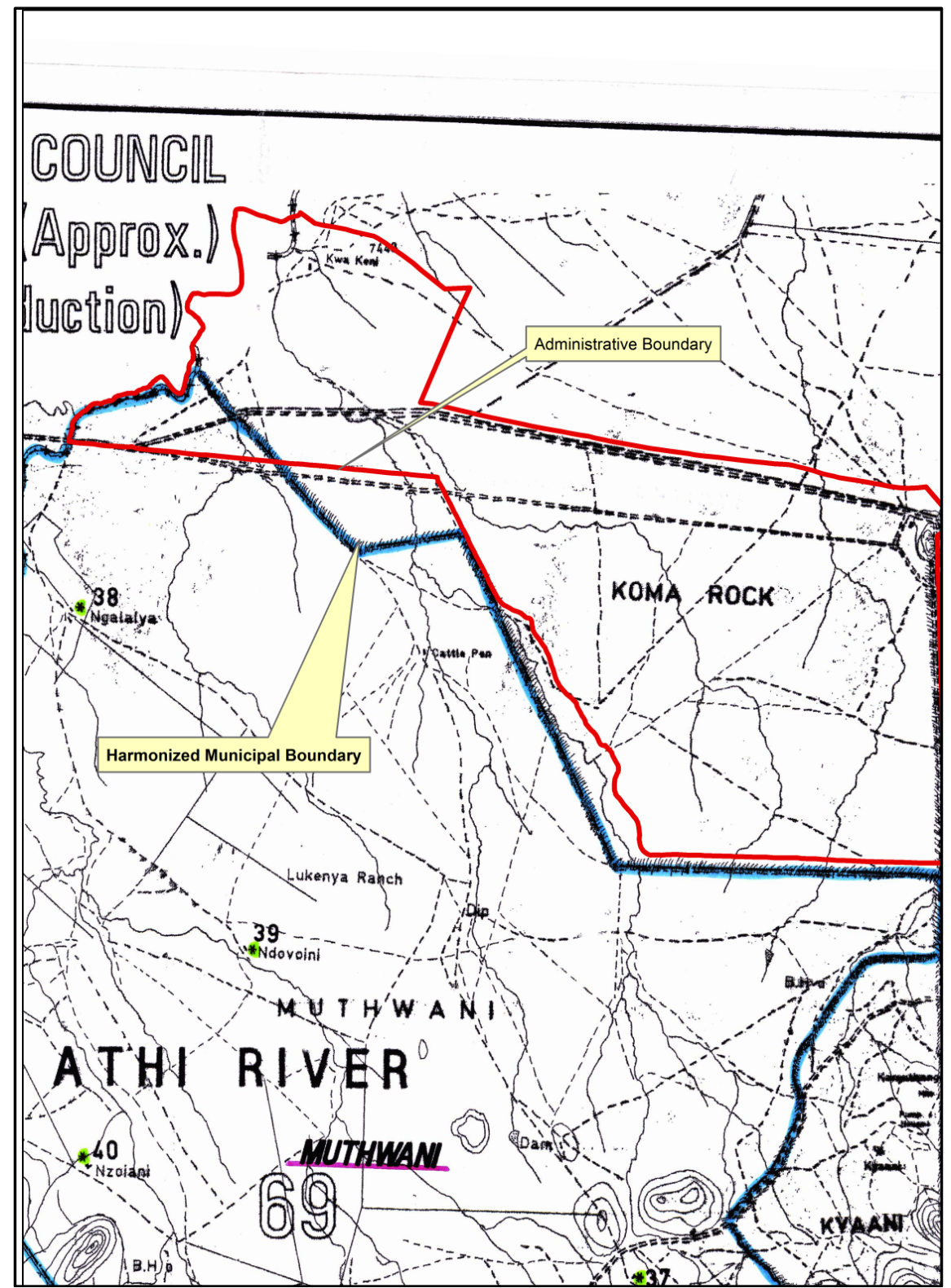

Figure 12. Overllapping boundary between Mavoko and Matungulu constituencies at Joska trading centre overlaid on existing HB maps.

show the boundary after rectification.

\subsection{Harmonization of CAW Boundaries}

The boundary between Kinanie and Muthwani CAW's had a gap, resulting into a disputed block as shown on Figure 14. In order to align the two boundary data sets, a field survey was carried out. This involved public consultation of the various stakeholders in the area, including but not limited to the area administrative officers, the school head teachers and their education counterparts, the IEBC Constituency Elections Coordinators, the County Surveyors and some residents. The boundary was picked as described in the field and plotted as shown on Figure 15 . 


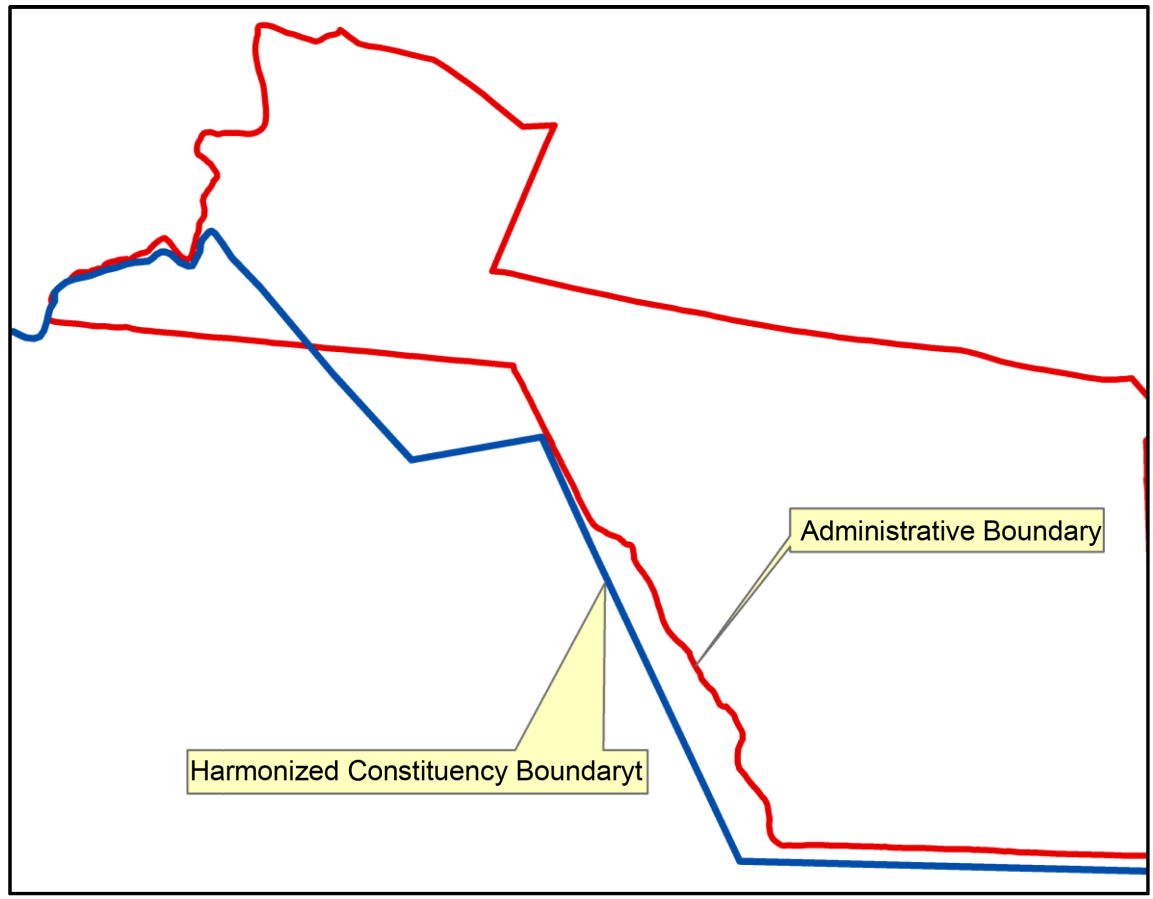

Figure 13. Harmonization of constituency boundaries using existing HB maps.

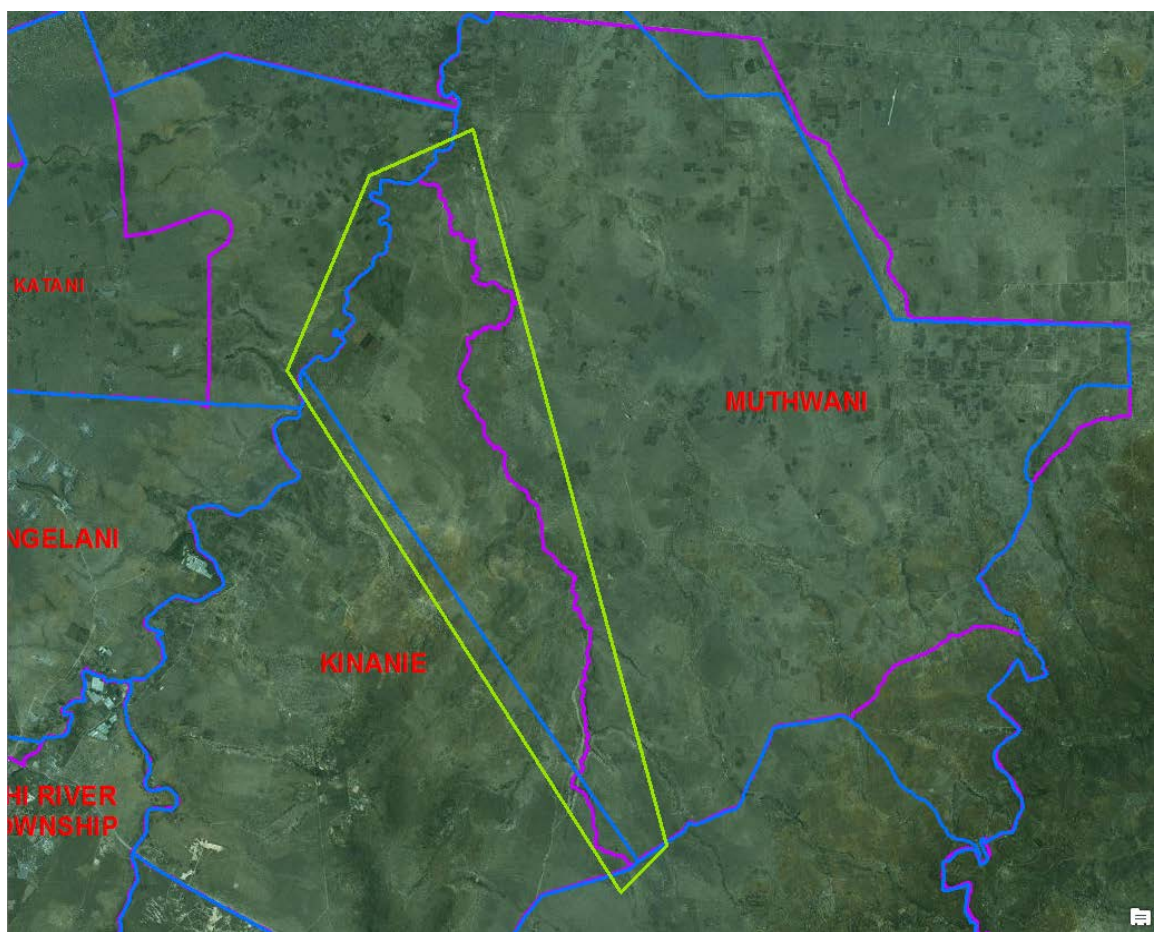

Figure 14. Disputed CAW boundary resulting into a disputed block.

\subsection{A Web Application}

The developed Web GIS portal is able to dispatch accurate information on time and consists of various useful GIS tools for spatial data visualization, analysis, querying and finally download data for use in mapping as base data. For the system to access the database, a Bitnami Wampstack Apache was downloaded and 


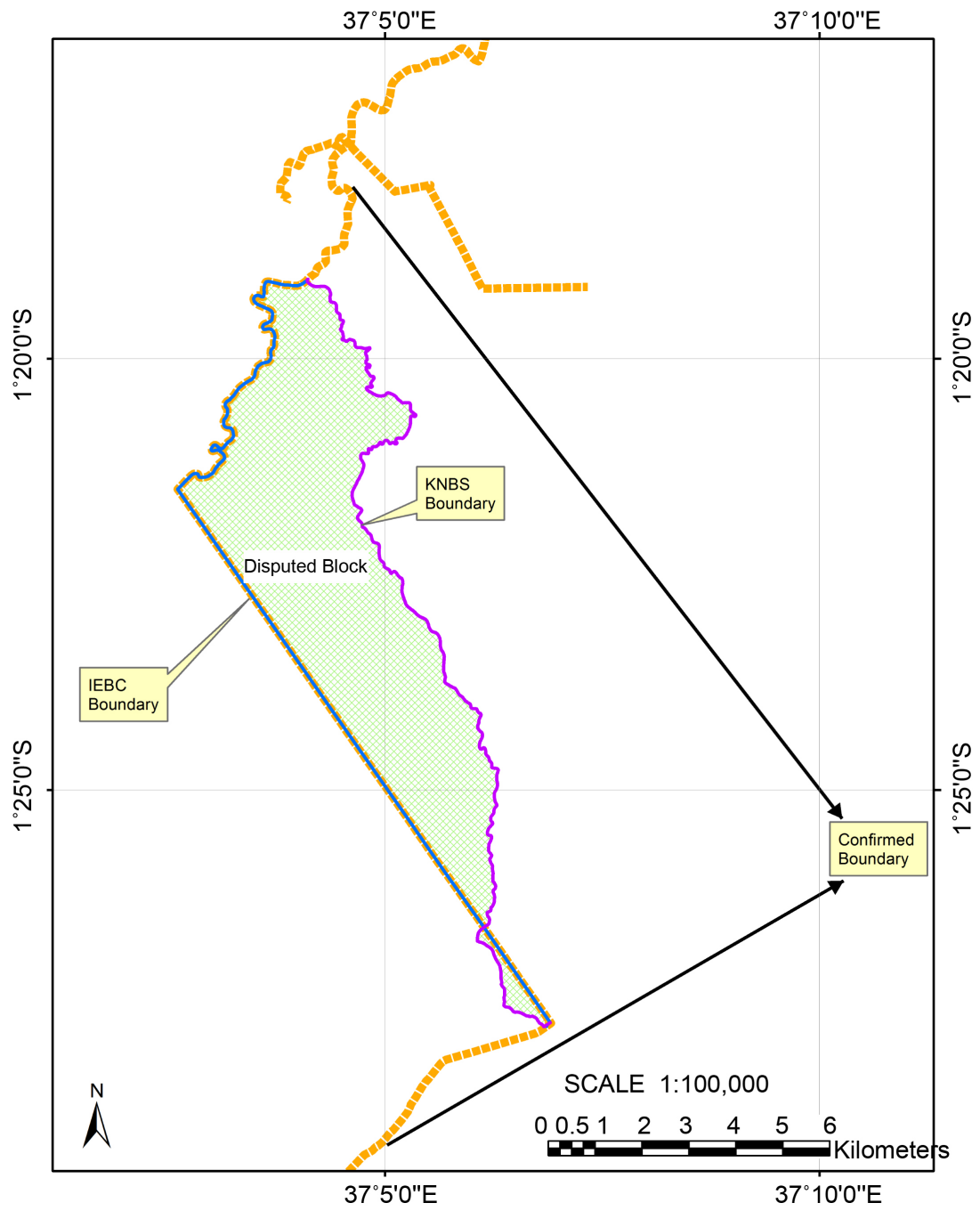

Figure 15. Harmonized CAW boundary as a result of field survey.

installed, upon whose launch the log in user interface show in Figure 16. The results obtained through interacting with the developed web are diagrammatically illustrated in Figure 17, is the proposed harmonized boundary for Mavoko Constituency as a result of the research. Figure 18 depicts the interactive user interface with the boundaries, roads, markets and the polling stations with the various markets highlighted.

\section{Conclusions and Recommendations}

\subsection{Conclusions}

The study led to the creation of a single sub location layer for the Mavoko Constituency. The Geo-Portal created was able to facilitate basic functionalities of search and data retrieval in simple and fast data access, data analysis and re use of the sub location data in order to fulfill various functions and so as to suit these objectives. Therefore the research used a simple interface that would allow for easy information dissemination to all. Three categories of users were envisioned: 1) Those who would want to know boundary information in relation to places. 


\section{WELCOME MAVOKO CONSTITUENCY HARMONIZED BOUNDARY MAP}

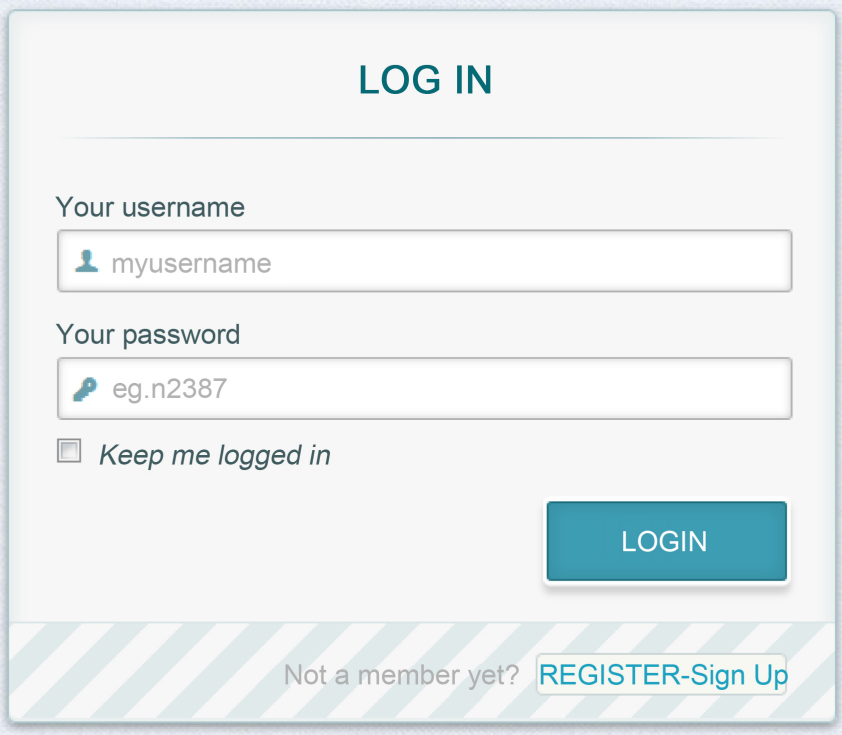

Figure 16. The Geo-portal log in page.

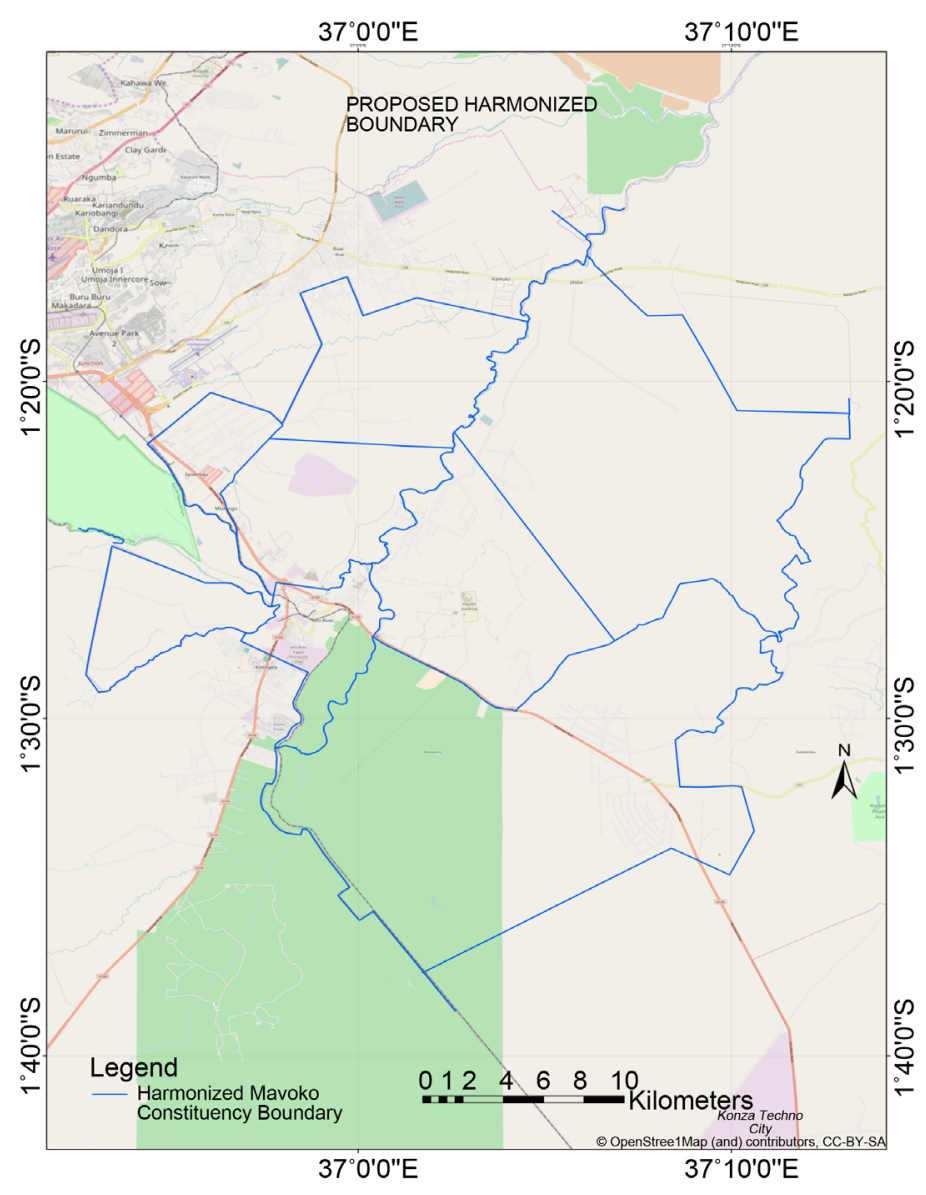

Figure 17. Proposed mavoko constituency harmonized boundary on an open street base map. 


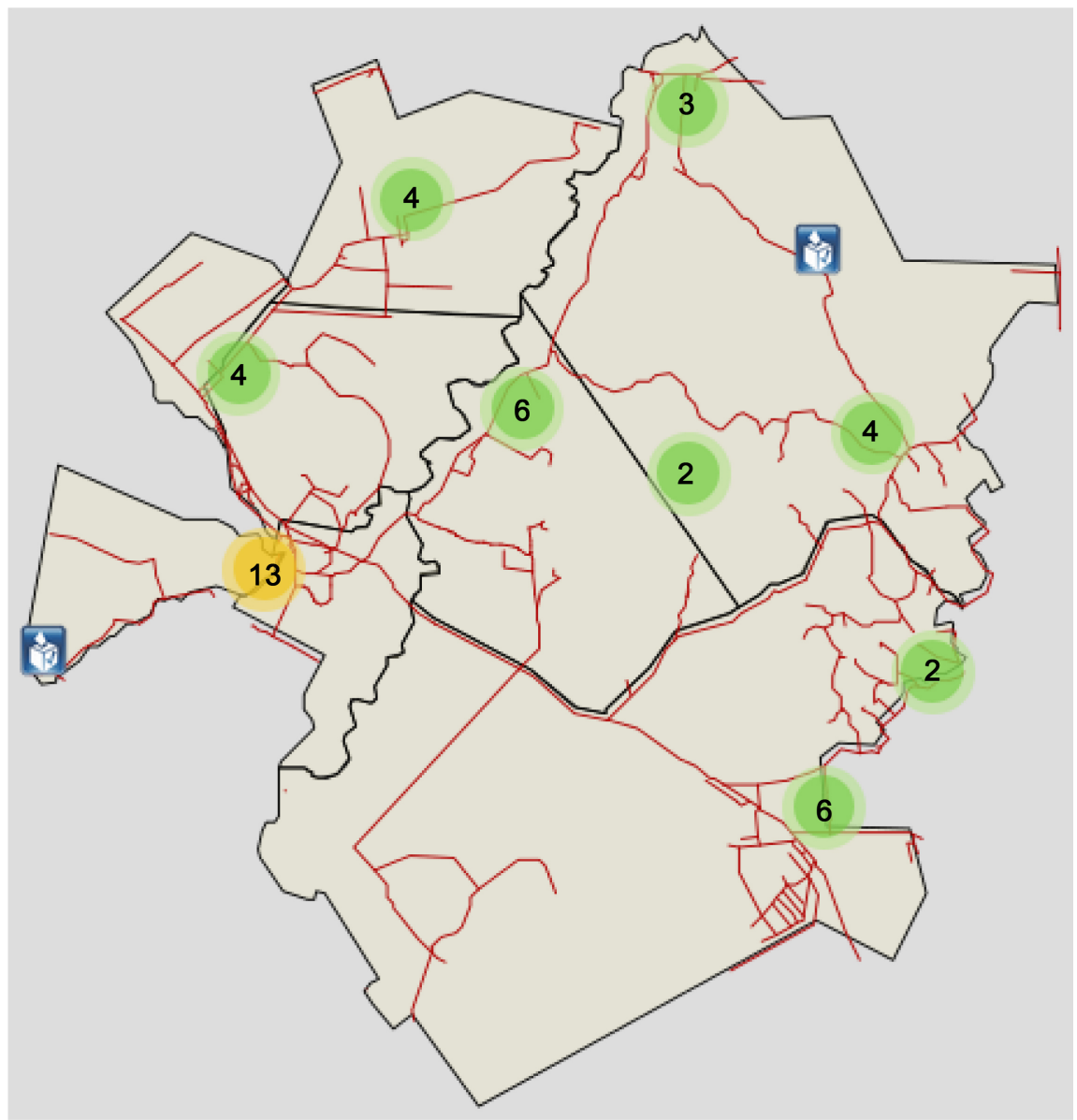

Figure 18. Proposed harmonized boundaries, roads and polling stations.

2) Those who would want to analyze the boundaries therefore download the data. 3) Those who would want to add more information into the platform.

\subsection{Recommendation and Future Research}

The Kenya National Spatial Data Infrastructure (KNSDI) set up standards for carrying out Geo spatial work in Kenya. However very little was set in terms of alignment on boundaries by the various government departments in carrying out the various tasks. The research recommends that the IEBC, Kenya International Boundaries Office (KIBO), the Survey of Kenya (SoK), KNBS and the relevant department in state department of interior to work together and come up with a harmonized data set for the country. The methodology on boundary harmonization adopted in this research if adopted for this task can lead to a harmonized boundary in Kenya. Once the sub location data set is created, checked and authenticated then it can be used in future by the various public and private bodies or individual for any kind of mapping as base data. This will ensure harmony in the data used and avoid conflicts of spatial data hence boundary dispute experienced in many parts of the country. Some unique challenges could be experienced in areas with unique case of conflict like the international boundary in some instances and some historical issues that require negotiations 
and goodwill other than the scientific methods suggested. The web based portal if linked with the Kenya Open DataInitiative (KODI) network can be shared by for use by many people.

\section{Acknowledgements}

The authors' wish to express their sincere gratitude to all the persons who in one way or another gave constructive critiques and comments to this paper.

\section{References}

[1] The Constitution of Kenya (2010) Nairobi: National Council for Law Reporting, Chapter 89 on IEBC. www.kenyalaw.org

[2] Population Census Data (Figures). http://www.knbs.or.ke/index.php?option=com_content\&view=article\&id=371:2009 -kenya-population-and-housing-census-analytical-reports\&catid=82\&Itemid=593

[3] Wadembere, I., and Ogao, P. (2004) Overcoming Object Misalignment in Geo-Spatial Datasets. Journal of Geographic Information System.

[4] https://maptimeboston.github.io/leaflet-intro/

[5] The PostgreSQL Global Development Group (n.d.) postgresql.org/docs. Retrieved 10 13, 2016. https://www.postgresql.org/docs/9.3/static/

[6] http://postgis.refractions.net/documentation/manual

[7] Parliament (1992 (Revised 2012)) Districts and Provinces Act. www.kenyalaw.org

[8] Agafonkin, V. (2015) Using GeoJSON with Leaflet. Retrieved October 12, 2016. http://leafletjs.com/examples/geojson

\section{Submit or recommend next manuscript to SCIRP and we will provide best} service for you:

Accepting pre-submission inquiries through Email, Facebook, LinkedIn, Twitter, etc. A wide selection of journals (inclusive of 9 subjects, more than 200 journals)

Providing 24-hour high-quality service

User-friendly online submission system

Fair and swift peer-review system

Efficient typesetting and proofreading procedure

Display of the result of downloads and visits, as well as the number of cited articles

Maximum dissemination of your research work

Submit your manuscript at: http://papersubmission.scirp.org/

Or contact jgis@scirp.org 